\title{
O antropoceno e a música dos insetos
}

\author{
Pedro Amorim Filho \\ UFRB, Santo Amaro - BA, Brasil ${ }^{1}$
}

\begin{abstract}
A auto-percepção do ser humano como distinto dos demais seres está na base da ameaça aos ecossistemas posta pelo antropoceno. O antropoceno é, portanto, um dilema do humanismo. Seria a relação entre expressão e comunicação interespécies (como o contato com o mundo estético dos insetos) capaz de ativar uma escuta crítica e uma reflexão perspectivista sobre o antropoceno? A partir de referências multidisciplinares (bioacústica, etologia, entomologia cultural, biomusicologia), discutem-se as implicações de uma possivel música dos insetos, decorrente das reflexões surgidas no processo de pesquisa do projeto 'entomúsica' (um neologismo fundindo o radical 'entomo' [inseto], e música). Entomúsica, neste contexto, significa: música feita por, com ou para os insetos.
\end{abstract}

Palavras-chave: antropoceno, zoomusicologia, antropomorfismo, perspectivismo

Este texto é resultado de reflexões surgidas no processo de pesquisa para o projeto de arte sonora intitulado 'entomúsica' . A obra parte de algumas questões que desencadearam o processo de pesquisa, cujo resultado parcial é apresentado neste texto: Seria possivel criar uma instalação sonora com insetos como o seu público alvo? Ou seja: em vez de criar música com sons de insetos para fruição humana, processo bastante explorado por alguns artistas (Rothenberg 2013), seria possivel criar uma música que pudesse ser apreciada por insetos? Como se dá a estésis dos insetos? Como são os perceptos e afetos desses artrópodes? Ou melhor: há algo como uma sensibilidade ar-

1 Centro de Cultura, Linguagens e Tecnologias Aplicadas, Universidade Federal do Recôncavo da Bahia (CECULT). Contato do autor: pedrofilhoamorim@ufrb.edu.br

2 Link para página do projeto: https://ritmopeia.wordpress.com/happeningsactionssituations/entomusica/ 
tística nos insetos ou isso é uma distorção antropomórfica? E, independente da possibilidade ou não de avaliar como seria sua fruição, seria possível criar música ou arte sonora em colaboração criativa com insetos?

O texto se divide em cinco seções, organizadas da seguinte forma: $\mathrm{Na}$ seção 1 , coloca-se a questão do antropoceno como um dilema do homem moderno ocidental e a possibilidade de lidar com esse dilema a partir do reconhecimento de "personitudes" não-humanas. Na seção 2, discute-se a necessidade de ativar uma escuta do mundo, em paralelo à dominância da visão de mundo que culmina no antropoceno. Isso nos leva à questão abordada na seção 3, onde se evoca a necessidade de lidar com o mundo não mais exclusivamente a partir da escala humana, mas buscando compreender a formação e os ecos ancestrais de uma escala mundana. Todas essas considerações, visam a estabelecer o contexto conceitual apropriado para entrar na discussão específica, na seção 4, sobre os campos de estudos em que se insere a pesquisa da 'entomúsica', principalmente os desenvolvimentos e discussões da zoomusicologia. Por fim, na seção 5, apresento brevemente uma descrição do processo criativo do projeto 'entomúsica', com exemplos de resultados obtidos até o momento.

\section{O dilema do antropoceno}

O antropoceno, concebido como uma nova era geológica resultante da intensa interferência humana no planeta (Crutzen e Stoermer 2010), se apresenta como um dilema: o projeto humanista levado às últimas consequências e voltando-se contra si mesmo. O dilema do antropoceno resulta de uma concepção antagônica do humano como ser distinto e superior às outras espécies e em permanente oposição contra a natureza selvagem. Essa concepção se expressa nos fundamentos do pensamento científico moderno, desde o cogito cartesiano até a própria (auto)classificação na taxonomia biológica como homo sapiens.

Esse dilema, que vem se tornando dramático à medida em que os sinais de um colapso ambiental iminente são cada vez mais atuais e menos hipotéticos, se relaciona diretamente com o que Ingold (2015:32) caracteriza como "talvez a contradição fundadora de todo o edifício ocidental - nomeadamente que não há absolutamente como compreender o envolvimento criativo dos seres humanos no mundo material a não ser extraindo-se dele”.

Em face dos prognósticos catastróficos do antropoceno, alguns dos primeiros cientistas que propagaram o termo já alertavam para os desafios significativos colocados para a humanidade, como o de "desenvolver uma estratégia mundialmente aceite que leve à sustentabilidade dos ecossistemas 
contra as tensões induzidas pelo homem"3 (Crutzen e Stoermer 2010:18). No entanto, as próprias implicações ocultas dessa proposição evidenciam o caráter ambíguo do antropoceno: a quem nos referimos quando mencionamos o "homem" e a "humanidade"?

[....] o antropoceno revela que a concepção padrão de anthropos é demasiado estreita e difusa, uma vez que não explica totalmente a ampla associação de elementos não humanos implicados nas "atividades humanas" culpáveis, nem especifica adequadamente quais os seres humanos que devem ser responsabilizados. (SHAW 2018)

O antropoceno resulta da ação humana, mas não de todo e qualquer humano: sobretudo do humano moderno ocidental. Esse ser humano se coloca como termo principal de uma escala de "pessoalidade" que, até pouco tempo atrás, chegava a excluir ou questionar a humanidade de alguns seres (hoje considerados plenamente) humanos. Mulheres, crianças, pessoas de etnias diferentes da sua, foram durante muito tempo consideradas pelo homem moderno ${ }^{4}$ como humanos imperfeitos ou talvez até não humanos. Essa escala que de fato mede a "inumanidade" dos outros seres - pode ser entendida em termos de um afastamento da categoria principal de humano: partindo do homem moderno, passando pelos "outros", seguindo com primatas, mamíferos, reptilianos, insetos... e assim até outros reinos distantes: vegetal, mineral, fungi...

Mas o homem moderno, segundo suas próprias definições científicas, acaba por se definir como um animal: um primata supostamente mais desenvolvido em alguns aspectos do que os outros animais da mesma ordem. A classificação biológica do ser humano e seus parentes mais próximos tem gradações escalares detalhadas e sofreu mudanças significativas na virada do século XXI. Atualmente considera-se que o gênero homo (do qual os humanos são a única espécie viva) faz parte da tribo hominini, que inclui primatas da espécie pan (chimpanzés e bonobos), que por sua vez está inserida na família dos grandes primatas, hoje chamados hominideos (família hominidae), que inclui gorilas e orangotangos e, por fim, todas essas espécies pertencem à chamada superfamília hominoide, que inclui gibões além das espécies anteriormente mencionadas (Wood 2010). Como vemos, o radical homo-/ homi- que pertencia exclusivamente ao homo modernus até recentemente, agora designa parentes próximos e até não tão próximos ${ }^{5}$.

3 "develop a world-wide accepted strategy leading to sustainability of ecosystems against human induced stresses will be one of the great future tasks of mankind" (tradução do autor, esta e todas as demais).

4 Neste texto, a expressão "homem moderno" será tratada como redução de: homem branco moderno ocidental (ou do norte global, para usar a expressão de Boaventura S. Santos). O conceito de homo modernus é empregado num sentido similar por Denise Ferreira da Silva (2007).

5 O GAP (Great Apes Project), por exemplo, é uma organização internacional de primatologistas, antropólogos e outros que defendem uma 'Declaração dos Direitos dos Grandes Primatas' das Nações Unidas, que conferiria direitos legais básicos aos grandes símios não humanos: chimpanzés, bonobos, gorilas e orangotangos. Cf. https://www.projetogap.org.br/ 
A auto-percepção exclusivista do humano moderno ocidental não deixou de provocar problemas de metodologia científica. O receio de atribuir características humanas a outras espécies de animais foi durante algum tempo um fator de atraso em algumas áreas da biologia. O primatologista Frans De Waal exemplifica essa situação, falando sobre o papel de pesquisadores japoneses, como Kinji Imanishi, no desenvolvimento dos estudos do comportamento de primatas:

[...] sua abordagem foi muito inovadora, graças à ausência do dualismo homem-animal. Sendo o produto de uma cultura que não distingue a espécie humana como a única com alma, Imanishi não teve problemas com a ideia de evolução nem com a dos seres humanos como descendentes de macacos. [...] A boa recepção desta parte da teoria evolucionária - a continuidade entre todas as formas de vida - implicou que as questões sobre o comportamento animal fossem desde o início não contaminadas por sentimentos de superioridade e aversão à atribuição de emoções e intenções que paralisavam a ciência ocidental. Assim, os japoneses não hesitaram em dar um nome a cada animal ou em assumir que cada um tinha uma identidade e personalidade diferentes. (De Waal $2001: 116)^{6}$

Dentro dessa discussão, De Waal descreve formas de antropomorfismo nas ciências biológicas, relacionadas com atitudes dos pesquisadores, entre as quais destaca o antropomorfismo antropocêntrico (ou "ingênuo") e o antropomorfismo "animalcêntrico", que tenta entender os animais nos seus próprios termos. O oposto ao antropomorfismo seria a "antropo-negação" [anthropodenial, que "baseia-se no pressuposto de que é mais seguro errar pelo lado da diferença do que da continuidade" (De Waal 2001:77) ${ }^{7}$. Essa negação é a caracteristica mais marcante da atitude autoindulgente dos pesquisadores ocidentais: "Antropomorfismo e antropocentrismo nunca estão muito afastados: o primeiro é em parte um "problema" devido ao segundo" (De Waal 2001: 64) ${ }^{8}$.

A questão das pessoalidades (ou da "personitude") não-humanas está presente de maneira ainda mais intensa no perspectivismo multinaturalista ameríndio, "uma teoria cosmopolitica que imagina um universo povoado por diferentes tipos de agências ou agentes subjetivos, humanos como não-humanos" (Viveiros de Castro 2015: 43). Essa teoria, amplamente referenciada nas etnografias de povos indígenas das Américas, concebe todos os animais e demais seres como "virtualmente pessoas": "A "personitude" e a "perspectividade" - a capacidade de ocupar um ponto de vista - são uma questão de grau,

6 " [...] his approach was very innovative, thanks to the absence of human-animal dualism. Being the product of a culture that doesn't set the human species apart as the only with a soul, Imanishi had trouble with neither the idea of evolution nor that of humans as descendants of apes. [...] The smooth reception of this part of evolutionary theory - the continuity among all life forms - meant that questions about animal behavior were from the start uncontaminated by feelings of superiority and aversion to the attribution of emotions and intentions that paralyzed Western science. Thus , the japanese did not hesitate to give each animal a name or to assume that each had a different identity and personality".

7 "based on the assumption that is safer to err on the side of difference than of continuity".

8 "Anthropomorphism and anthropocentrism are never far apart: the first is partly a "problem" due to the second". 
de contexto e de posição, antes que uma propriedade distintiva de tal ou qual espécie" (Viveiros de Castro 2015:46).

Se para o homem moderno a escala de personitude parte do homo sapiens e vai se afastando, no perspectivismo ameríndio o núcleo de pessoalidade é distribuído no universo entre todos os corpos, aqui entendidos não como "uma fisiologia distintiva ou uma anatomia característica" e sim como "um conjunto de maneiras ou modos de ser que constituem um habitus, um ethos, um etograma [...] feixe de afetos e capacidades" (Viveiros de Castro 2015:66). Há uma diferença fundamental entre "pessoa" e "humano", dentro de implicações etnocêntricas presentes nas culturas amerindias:

Esse fato de que a condição de pessoa [...] possa ser tanto "estendida" a outras espécies como "recusada" a outros coletivos de nossa espécie sugere, de saída, que o conceito de pessoa - centro de intencionalidade constituído por uma diferença de potencial interna - é anterior e superior logicamente ao conceito de humano. (Viveiros de Castro 2015:47).

Lidar com os desafios do antropoceno requer um questionamento da visão de mundo que coloca o homem como medida de todas as coisas. Para escapar às limitações impostas por essa concepção antropocêntrica, é preciso abordar as diferentes escalas que compõem o mundo, medido pela diversidade dos seres, coisas e eventos entre si, assim como diferentes modos de estar no mundo. A proeminência das imagens e do registro visual na cultura moderna é um desses modos dominantes que precisa ser abordado em detalhe.

\section{'Visăo de mundo' e escuta do mundo}

A tradição científica moderna, em grande medida, reproduz uma desconfiança ancestral contra a "ilusão dos sentidos", ao mesmo tempo em que, tacitamente, supervaloriza um deles (a visão) em detrimento dos outros. Isso se evidencia em um campo de conceitos-chave metaforizados a partir da visão

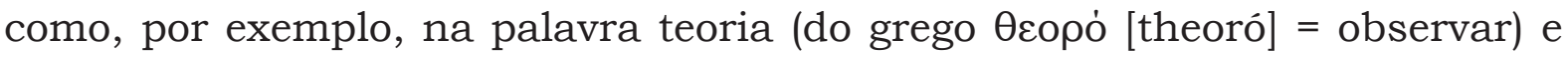
na própria expressão 'visão de mundo'. A objetificação do mundo, uma das características marcantes do homem moderno, que se define como sujeito dessa relação, se adapta bem - ou talvez decorre da - hegemonia da metáfora visual sobre os demais sentidos. A escuta e, mais ainda, a propriocepção são comumente relegadas a fontes de dados imprecisas no paradigma científico clássico, ao passo que os gráficos e descrições visuais (além do texto escrito) são auxiliares constantes na descrição de fenômenos de naturezas diversas.

A condição principal para a objetificação do mundo, sua conversão em "coisas" (incluindo imagens, ideias...) é a supressão da percepção do tempo. A metafísica clássica ocidental costuma observar os fenômenos sub specie aeternitatis [do ponto de vista da eternidade], suprimindo o caráter temporal diacrônico, para fazer inferências universais válidas. Nas palavras de Joanna Zylinska: "Na tentativa de compreender a passagem do tempo, fazemos incisões nele com nossos aparelhos proprioceptivos e cognitivos e depois re- 
passamos os produtos dessas incisões como imagens do mundo" (Zylinska 2014:26). Uma perspectiva capaz de lidar com os desafios do antropoceno (afinal concebido como novo período do tempo geológico), deve trazer o plano da intuição temporal para o centro do debate.

A escuta propicia uma base metafórica viável para pensar a realidade temporal, já que evoca um mundo de eventos, contrapondo os objetos da visão. Não que um sentido possa se sobrepor totalmente ao outro ou que possam operar independentemente, em termos práticos, mas a ênfase cultural em um deles (a visão) pode embotar relativamente a percepção dos demais. Para chamar a atenção aos aspectos auditivos do mundo, muitos artistas sonoros e pesquisadores de áreas diversas (da biologia às ciências humanas) vêm utilizando conceitos como: paisagem sonora (Schafer 2011), biofonia (Krause 2013), cosmofonia (Chattopadhyay 2018).

Ainda assim, falar da escuta do mundo, é falar de um mundo, a princípio, humano. Se queremos especular como é ser inseto ou conjeturar se os insetos fazem música, podemos começar perguntando: como "ouvem" os insetos? As aspas no verbo ouvir são intencionais. As discussões no campo da entomologia (ramo da biologia que estuda os insetos) trazem pistas importantes sobre isso: "quando se trata de descrever e analisar sons de insetos e seu uso na comunicação, é quase impossivel evitar problemas de antropomorfismo"9 (Drosopoulos e Claridge 2006:3).

Na biologia, o som em geral é definido como "vibração transmitida através de meios fluidos, como ar e água", mas essa definição "claramente exclui a vibração sobre substratos sólidos, que, agora se sabe, são amplamente usados na comunicação dos insetos"10 (Drosopoulos e Claridge 2006:4). Trata-se de uma questão conceitual importante, já que o conceito de "som" (e seus limites: infrassom e ultrassom) em geral é considerado apenas a partir da perspectiva sensorial humana, o que se converte num problema 'grave' (ipsis litteris) de antropomorfismo antropocêntrico.

Os termos "ultrassom" e "ultrassônico", embora úteis, são antropomórficos e referem-se a vibrações com frequências acima das detectáveis pelo ouvido humano nu [unaided human ear]. Uma grande variedade de animais, incluindo muitos insetos (p. ex.: muitos grilos, cigarras, etc.), tem tessituras de sensibilidade acústica que se estendem bem acima da do ouvido humano [...]. Claramente uma definição tão limitada de som não é útil no estudo científico do comportamento animal (Drosopoulos e Claridge 2006:3) ${ }^{11}$.

9 when it comes to describing and analysing insect sounds and their use in communication, it is almost impossible to avoid problems of anthropomorphism.

10 A strict definition of sound, as vibration transmitted through fluid media, such as air and water, clearly excludes vibration through solid substrates which are now known to be very widely used in insect communication [...].

11 The terms "ultrasound" and "ultrasonic", though useful, are anthropomorphic and refer to vibrations having frequencies above those detectable by the unaided human ear. A wide variety of animals, including many insects (e.g. many bushcrickets, cicadas, etc.), have ranges of acoustic sensitivity which extend well above that of the human ear and ultrasound is critical in the lives of many animals [...] Clearly such a limited definition of sound is not useful in the scientific study of animal behaviour. (DROUSOPOULOS et al, p.3) 
O fato da audição de muitos insetos (e outros animais) captar faixas de frequência mais altas (ou seja: mais agudas) tampouco implica exatamente numa limitação humana. A comparação entre audições humanas e não-humanas incorre igualmente no risco do antropomorfismo ingênuo, quando se considera as diferenças a partir da média de audição humana e se atribui caraterísticas de deficiência ou superpoder às faixas auditivas discrepantes:

[...] ao tomar a faixa de frequência audivel como critério, a audição humana não se compara tão mal com a de outras espécies como é freqüentemente alegado. Não podemos ouvir as freqüências ultrabaixas acessíveis a um elefante, mas podemos ouvir outras consideravelmente mais altas. E enquanto nossos ouvidos são incapazes de processar informações de alta frequência como um morcego poderia fazer, sua audição consciente já está cortada a $2.000 \mathrm{~Hz}$ na extremidade inferior do espectro, onde os humanos ainda podem processar uma grande quantidade de informações. (Cory e Fischer 2015:91) ${ }^{12}$

Essa discussão vai culminar na distinção entre os conceitos de som e vibração, adotada por alguns estudiosos dos sons de insetos e rejeitada (ou ignorada) por outros. Trata-se de mais uma questão fundada no antropomorfismo, já que os autores que consideram sons e vibrações como fenômenos distintos se valem das características vibratórias (limites de frequência e meio de transmissão) da percepção humana para estabelecer a distinção.

Alguns autores tentam claramente separar som e vibração como dois fenômenos diferentes, outros adotam uma visão mais ampla. Muitos problemas em biologia não são problemas reais, mas resultam do desejo humano de criar definições estritas e exclusivas para partes de fenômenos efetivamente contínuos. ${ }^{13}$

As diferenças de escuta entre humanos e insetos não se limitam às faixas de frequência no contínuo som-vibração. Muitos insetos têm órgãos especiais para captar 'sons' ou vibrações em meios fluidos e sólidos, muitos também têm ouvidos timpânicos, com funcionamento similar ao nosso, mas que podem estar distribuídos em outras partes do corpo, não apenas na cabeça (nas articulações das pernas por exemplo) e em número maior que um par (Drosopoulos e Claridge 2006).

Com base nesses dados, nota-se que não é tarefa simples colocar-se na perspectiva sensível dos insetos. Ainda assim, podemos identificar semelhanças entre nosso modo de estar no mundo e o deles. A audição humana tampouco é um sentido somente localizado nos ouvidos (Smith 2002; Takahashi 2011): com amplitude suficiente, sons muito graves podem fazer vibrar partes do corpo, sobretudo a caixa torácica, e vibrações abaixo de $20 \mathrm{~Hz}$ (infras-

12 In reality, when taking audible bandwidth as a criterion, human hearing doesn't compare quite as badly to those of other species as is often claimed. We can't hear the ultra-low frequencies accessible to an elephant, but we can hear considerably higher ones. And while our ears are incapable of processing high-pitch information the way a bat could, their conscious hearing is already cut off at $2,000 \mathrm{~Hz}$ on the lower end of the spectrum, where humans can still process a wealth of information. In the big picture, humans neither have the most refined pair of ears - nor do they have the worst.

13 Some authors attempt clearly to separate sound and vibration as two different phenomena, others take a wider view. Many problems in biology are not real ones, but result from the human desire to make strict and exclusive definitions for parts of effectively continuous phenomena. 
sons) são percebidas como tremulações ou pulsações sequenciais (Smith 2002; Takahashi 2011). As diferenças perceptivas entre humanos e insetos, de forma análoga à diferença estabelecida entre sons e vibrações, ou entre som, infrassom e ultrassom, dependem de muitos fatores, fenomênicos e conceituais, mas são sobretudo diferenças de escala.

\section{Escala humana e escalas mundanas}

A visão antropocêntrica do mundo opera numa escala cujas medidas (a média) é determinada pelas extensões, durações e intensidades percebidas pelo ser humano. O que ultrapassa ou fica aquém dessa média acaba sendo classificado como fenômeno de natureza distinta como vimos no caso das definições de som. Esse antropocentrismo, como já foi dito, é característico do homem moderno. Um bom exemplo disso é encontrado na teoria musical de um filósofo pré-moderno, Boécio, que em seu tratado De Institutione Musica (do século VI) afirma serem três os "tipos de música descritos pelos estudiosos": (1) a música "produzida por certos instrumentos, como a cítara, o aulos e outros que acompanham as canções", musica instrumentalis, (2) a musica humana, harmonia dos humores corporais (Castanheira 2009:65) e (3) a musica mundana:

[...] perceptível sobretudo pelo que é visto no próprio céu, ou na combinação dos elementos, ou na sucessão de estações, pois como é possivel que uma máquina tão veloz como a do céu se mova em uma trajetória muda e silenciosa? Ainda que seu som não chegue aos nossos ouvidos, porque por muitas causas é necessário que assim seja, não é possível, contudo, que um movimento tão veloz de corpos assim volumosos não produza absolutamente nenhum som (Castanheira 2009: 65-66).

É interessante observar como Boécio não baseia sua concepção de som (e de música) na percepção humana, enquanto para o paradigma moderno e "desencantado" do mundo (Chua 1999), apenas a música instrumental pode ser considerada real. Além disso, pelo conceito de musica humana (harmonia do corpo) percebe-se que a música é um fator transcendente de organização do mundo e não apenas uma 'arte dos sons'. Categorias análogas às descritas por Boécio têm sido aplicadas em incursões teóricas atuais. ${ }^{14}$ Assim, em paralelo à escala humana, podemos explorar também a escala mundana, como medida de tudo que transcende, em extensão, duração ou intensidade, as medidas de vivência humana.

Os conceitos de música 'humana' e 'mundana' são trazidos na tentativa de falar sobre o estar-no-mundo como ocorrência (diferente da existência, do

14 Numa busca por "musica mundana" ou "musica humana" na internet, muitos resultados são pesquisas e teorias em áreas como embriologia e astronomia. Estariam no escopo da musica humana disciplinas e metodologias como a ritmanálise (Lefebvre 1991), a cronobiologia (Marques 2012) e estudos sobre fundamentos biológicos da musicalidade humana e animal. Conceitos como os de biofonia e cosmofonia, coincidem fundamentalmente com a ideia expressa pela musica mundana. 
ser-no-mundo), ${ }^{15}$ que implica em se inserir como mais um evento, uma voz (fonia) em meio às outras. Mais do que um ser entre coisas, sujeito em meio aos objetos, humano em meio à natureza, somos partes numa polifonia de acontecimentos ${ }^{16}$. Na perspectiva ocidental moderna, a música, como fenômeno cultural universal, seria um traço exclusivo da "natureza humana". O conceito "pré-moderno" de música mundana assim como os de biofonia (Krause 2013) e cosmofonia (Chattopadhyay 2018), se alinham na inversão dessa perspectiva: música seria antes um fenômeno de natureza universal, presente em todas as culturas, humanas e mundanas.

\section{Música animal, zoomusicologia}

A intenção de fazer música com e para os insetos leva à necessidade de investigar campos do saber um tanto incomuns para músicos e musicólogos em geral. Num levantamento rápido, podemos listar uma série de disciplinas auxiliares e novas áreas de pesquisa que ajudam na configuração epistemológica do nosso tema, a começar por "interdisciplinas" ligadas aos campos da biologia, como bio-semiótica (Martinelli 2007; Fakotakis et al. 2006) bioacústica (Pavan 2008; Krause 2013), cronobiologia (Marques 2012) e zoomusicologia (Martinelli 2007; Taylor 2008/2011), sendo este último o ramo mais específico ao qual este trabalho adere:

Cunhada em 1983 pelo compositor francês François-Bernard Mâche, a zoomusicologia estuda os aspectos musicais dos sons animais. Segundo Mâche, "Se se verificar que a música é um fenômeno generalizado em várias espécies vivas além do homem, isto porá em questão completamente a definição de música, e mais amplamente a de homem e sua cultura, bem como a ideia que temos do próprio animal" (1983/1992:95). Sugiro uma definição provisória: a zoomusicologia é a valorização e a análise humana das qualidades estéticas dos sons animais não humanos. (Taylor 2008/2011) ${ }^{17}$

A definição provisória de Taylor não satisfaz, no entanto, a intenção "animalcêntrica" de emular a estésis dos insetos. A questão específica de fazer arte para animais é abordada de maneira exemplar por Fuller (2010), que

15 A distinção semântica entre ser e estar, inexistente em algumas das principais línguas ocidentais, que sintetizam ambos os aspectos num só verbo (inglês "to be", francês "être", alemão "sein", etc) é de suma importância nesse argumento.

16 As ideias aqui apresentadas, como fonias, música mundana, etc, têm ressonância com as ideias de "mundo-tempo", o pensamento dos seres como eventos e a ideia de "linhas" defendidas por Ingold (2015).

17 Coined in 1983 by French composer François-Bernard Mâche, zoömusicology studies the musical aspects of animal sounds. According to Mâche, "If it turns out that music is a widespread phenomenon in several living species apart from man, this will very much call into question the definition of music, and more widely that of man and his culture, as well as the idea we have of the animal itself" (1983/1992: 95). I suggest a provisional definition: zoömusicology is the human valorization and analysis of the aesthetic qualities of non-human animal sounds." 
não apenas conceitua mas fornece exemplos práticos de arte produzida para fruição de animais não humanos. Sua definição se desloca da valorização humana da expressão animal (sons dos insetos, por exemplo) para a intenção (ainda humana) em se dirigir a outras espécies como sujeitos e não como objetos:

Arte para animais é arte com animais destinados como seus principais usuários ou público. Arte para animais não é, portanto, arte que usa animais como substrato ou portador, nem como objeto de contemplação ou uso. [...]. Não é a arte que [...] descreve animais para espectadores humanos, ou que incorpora animais em quadros vivos, mas o trabalho que se refere diretamente ao mundo perceptual de uma ou mais espécies animais não-humanas. ${ }^{18}$ (Fuller 2010:18)

A apreciação humana da musicalidade animal não é o único foco nas discussões do campo ainda incipiente, mas em franca evolução, da zoomusicologia. No compêndio intitulado The Origins of Music [As Origens da Música] (Brown et al. 1999), autores de diversas áreas (musicólogos, biólogos, antropólogos, arqueólogos, psicólogos, neurocientistas, etólogos e linguistas) investigam os fundamentos biológicos e cognitivos da musicalidade humana e animal. A "teoria dos chamados sincrônicos" [theory of synchronous calls], proposta por Merker nessa publicação, demonstra, por exemplo, a presença de sincronia de pulso (uma capacidade tida como exclusiva de humanos e mais recentemente observada em outros mamiferos) entre vaga-lumes, cigarras, grilos e outros animais como caranguejos e sapos (Cory e Fischer 2015:119). Sobre a questão das funções evolutivas da música em animais, autores como Mâche e Martinelli (Cory e Fischer 2015) são categóricos em afirmar que a diversão e o jogo musical são características animais independentes de associações com acasalamento ou sociabilidade (relações, aliás, presentes também nas músicas humanas). A necessidade de justificar comportamentos animais em termos de função biológica é mais uma faceta do antropocentrismo: "Os humanos evoluíram para existir além da mera função; será tão bobo sugerir que os animais também o fizeram? ${ }^{19 "}$ (Cory e Fischer 2015:28).

\section{Desenvolvimento do projeto 'entomúsica'}

A música animal pode ser ainda definida como "sons que os animais fazem para além da comunicação básica” (Cory e Fischer 2015:25). Considerando que os insetos possam apreciar sons e vibrações produzidas por humanos e já que esses sons, embora fazendo parte do mundo perceptivo dos insetos pelas características espectromorfológicas (Smalley 1986), não equivalem a nenhum sinal de comunicação, sendo produzidos 'apenas' para ser ouvidos/percebi-

18 Art for animals is art with animals intended as its key users or audience. Art for animals is not therefore art that uses animals as a substrate or a carrier, nor as an object of contemplation or use. [...] It is not art that [...] depicts animals for human viewers, or that incorporates animals into living tableau, but work that makes a direct address to the perceptual world of one or more non-human animal species. (FULLER 2010: 18).

19 Humans have evolved to exist beyond function alone; is it so foolish to suggest that animals have as well? 
dos e pelos seus afetos, "música" seria de fato uma definição razoavelmente precisa para descrever as composições e instalações do projeto 'entomúsica'.

A ideia surge em 2016, no contexto de um outro projeto focado na produção de intervenções artísticas em locais de vegetação urbana não planejada ("matos" $\left.{ }^{20}\right)$. Uma das primeiras ações pensadas para aquele projeto era uma instalação em um terreno baldio que simulasse animais ou seres fantásticos sonoros, que afetariam os passantes humanos nas redondezas dos matos. Durante esse periodo, numa conversa casual, uma amiga bióloga mencionou um trabalho de etologia que falava sobre o efeito da poluição sonora em espécies marinhas (Slabekoorn 2017). A partir de uma comparação em escala com os matos dos terrenos baldios, surgiu uma preocupação sobre o impacto (por mais sutil que fosse) que uma instalação sonora poderia causar na fauna local, especialmente nos insetos. Isso me levou a pensar na escuta e na produção sonora dos insetos, com a intenção de criar uma instalação atraente - ou pelo menos não agressiva - para esses seres.

Muitas pesquisas sobre audição e comunicação sonora dos insetos são desenvolvidas para criar armas, armadilhas e repelentes sonoros contra insetos (MacCagnan 2008; Yildiz et al. 2011). Algumas armadilhas sonoras, por exemplo, funcionam atraindo os insetos com ilusões auditivas a partir de sons gravados e reproduzidos no habitat, em geral cantos de acasalamento de espécies locais. Se é possivel atrair os insetos com sons, conjecturei ser possível levar adiante a intenção de utilizar dados e metodologias dessas pesquisas para criar peças musicais, ou seja, artísticas, a favor dos insetos.

\section{Pesquisa específica para instalaçăo}

Comecei então a planejar os aspectos técnicos de uma instalação sonora, implementados de acordo com dados sobre escuta, comportamento e comunicação dos insetos. Os detalhes técnicos da instalação, de certa forma, precederam a própria composição das "entomúsicas". Um esquema de montagem da instalação foi pensado, levando em consideração as primeiras intenções: produzir sons perceptiveis para os insetos (mas não necessariamente para humanos) e cuidar para que essas emissões sonoras não consistissem em agressão ou repulsão dos insetos no local.

Para obter um diagnóstico do espaço seria importante fazer um mapa sonoro do local escolhido, com gravações cruzadas através de microfones omnie unidirecionais, com resposta de frequência ultrassônica. Para coletar dados suficientes a ponto de identificar alguns tipos de inseto pelos seus sons, as gravações deveriam capturar momentos significativos do dia, de acordo com os ciclos de comportamento dos insetos. Gravações noturnas (incluindo o

20 "Mato" era o título do projeto, que foi idealizado em parceria com a artista Lia Cunha e previa a participação de diversos colaboradores, mas foi suspenso ainda na fase de pesquisa por uma série de motivos que não caberia detalhar aqui. 
crepúsculo e o amanhecer) captam uma paisagem sonora menos antropogênica, na qual é possivel identificar mais precisamente a atividade sonora dos insetos e, cruzando com dados ambientais e etológicos, tentar fazer um levantamento das espécies locais e da sua escuta e produção sonora. Por outro lado, também valeria a pena registar a fase de intensa atividade humana para efeitos de comparação e de análise das diferenças dos períodos. Essa ritmanálise (Lefebvre 1991) do 'mato' ajudaria na reflexão sobre a interação entre o mundo sonoro dos insetos e dos humanos. A escolha de zonas de mato urbano, nesse caso, é intencional. Certamente é possivel criar entomúsica na natureza selvagem, em áreas não urbanizadas, mas faz parte do conceito da obra a relação com insetos que já convivem com seres humanos.

O equipamento ideal para esse mapeamento incluiria detectores de morcegos e gravadores sólidos multipistas ou placas de som ligadas a computadores $^{21}$. Num projeto proposto para um edital de financiamento de instalação artística, apresentei três possibilidades de esquema técnico, listadas abaixo da mais sofisticada (menor perda de dados, maior precisão na captura, equipamento mais caro) à mais simples (pouca flexibilidade na captura, menor fidelidade, equipamento mais barato):

Opção A: 1 Microfone Ambisônico ligado a gravador multipistas (4 canais) com taxa de amostragem de $192 \mathrm{kHz}$, enviando dados ao sistema (processados pelo software PureData).

Opção B: 4 microfones condensadores omnidirecionais ligados ao sistema (placa de som + software PureData) com taxa de amostragem de $192 \mathrm{kHz}$, distribuídos em 4 canais.

Opção C: 2 (dois) gravadores estéreo (microfones condensadores omnidirecionais) ligados ao sistema (placa de som + sotware PureData) com taxa de amostragem de $192 \mathrm{kHz}$, com distribuição em 4 canais (gravador $1 \mathrm{~L}=1, \mathrm{R}=2$; gravador $2=\mathrm{L}=3, \mathrm{R}=4$ ).

A taxa de amostragem necessária para capturar ultrassons foi limitada a $192 \mathrm{kHz}$ pois a maioria dos gravadores de áudio profissionais sequer chegam a esse limite. Essa taxa permite capturar e editar frequências até aproximadamente $96 \mathrm{kHz}$, o que viabiliza ver (não ouvir, é claro) e editar uma certa gama de ultrassons em softwares de áudio, na visualização espectral. Não tendo sido contemplado com o financiamento, mas munido do equipamento à minha disposição, realizei testes de gravação com taxa de amostragem intermediária $(96 \mathrm{kHz})$ e pude identificar e transpor alguns ultrassons para a faixa de escuta humana. Algumas estruturas rítmicas identificadas coincidem com padrões de cantos de insetos. Na figura 1, um exemplo (já transposto e amplificado) onde vemos dois ritmos superpostos, produzidos provavelmente por insetos distintos:

21 Alguns detectores de morcegos podem gravar com taxas de amostragem (T.A.) altíssimas, de até $500 \mathrm{kHz}$, sendo capazes de detectar uma larga faixa de ultrassons. O preço desses dispositivos, no entanto, é proibitivo: um sistema com T.A. de $384 \mathrm{kHz}$ chega a custar U\$ 449,00 (valores de dezembro 2020) e dispositivos mais completos podem custar até dez vezes mais: <https://batmanagement.com/collections/bat-detector-buyers-guide-active-detectors> 


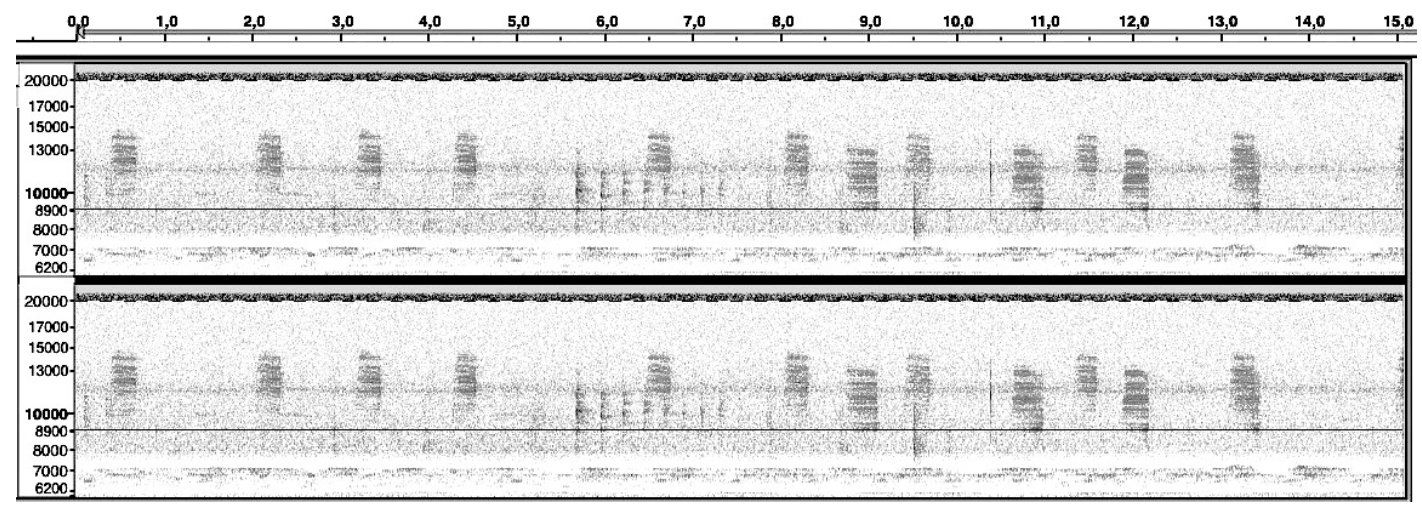

Figura 1. Espectrograma de gravação de insetos (do autor)

Na imagem do espectrograma vemos dois padrões: (1) manchas verticais mais densas situadas pouco acima da linha central ${ }^{22}$, e (2) linhas mais finas e mais próximas, perto do centro horizontal da imagem, sinalizando um canto mais acelerado e com ataques mais "staccato" em comparação com o outro. A partir dessas gravações e análises, parti para a edição e síntese de dados perceptivos (para insetos) que seriam difundidos no mato como micro-concertos. Não sabendo exatamente o que propor para a escuta dos insetos, recorri a procedimentos especulativos para imaginar possibilidades de composição de repertórios.

\section{Composiçöes das entomúsicas - processos de traduçăo}

A ideia básica de tradução mútua entre a música humana e a música dos insetos orientou o processo de composição das entomúsicas. A documentação desses processos, bem como os áudios e imagens, podem ser acessados no sítio web do autor ${ }^{23}$. Abaixo um resumo dos processos e alguns tipos de variação formal possiveis:

\section{Sons de insetos convertidos em música humana}

Gravação de paisagem sonora com sons de insetos e trajetos de escuta Variação 1 - sem intervenção

Variação 2 - com filtro espectral e transposição para emular a escuta do ultrassom

Variação 3 - manipulada para provocar experiência inédita no ouvinte humano (música concreta, eletroacústica, arte sonora, etc)

22 Para quem não tiver familiaridade com esse tipo de gráfico, a imagem está repetida em duas faixas verticalmente superpostas, cada uma reproduzindo um dos canais (direito e esquerdo) do som estéreo. Quando falo da linha central, me refiro à linha que divide cada uma dessas faixas ao meio e não ao espaço entre as duas faixas.

23 Acessivel pelo link: https://ritmopeia.wordpress.com/happeningsactionssituations/entomusica/ 
Esse exemplo foi uma gravação do trajeto entre uma rua movimentada e um terreno baldio próximo, com vegetação densa e intensa atividade sonora de insetos. Na gravação, feita com taxa de amostragem alta, é possivel identificar ultrassons (como explicado na sessão anterior) que foram posteriormente filtrados e transpostos para a faixa de audição humana, permitindo a escuta de insetos "inaudiveis".

\section{Música humana convertida em entomúsica}

Transformação de fonogramas de música humana em sons apreciáveis por insetos

Variação 1: aceleração (time stretch) de peça musical humana, com repetição periódica orgânica para emular canto de inseto.

Variação 2: organizar os cantos resultantes em sequências para montar um "concerto" para os insetos, expondo o ciclo completo em repetições orgânicas

Variação 3: composição mista: "concerto" com repetições internas

Realizei experimentos com alguns fonogramas acelerados 64 vezes (limite baseado na minha percepção auditiva). O resultado se assemelha a chiados de insetos como o grilo. Um dos fonogramas usados foi uma gravação do Voo do Besouro $^{24}$, de Rimsky-Korsakov. O mesmo processo foi realizado com outros fonogramas, de gêneros totalmente diferentes como samba-reggae, grindcore, etc, resultando sempre em sons análogos a emitidos por insetos, mas com características formais distintas. Alguns fonogramas foram acelerados até ficarem silenciosos para humanos, mas provavelmente audiveis para insetos.

\section{Conclusăo}

Entomúsica é uma obra em progresso que vem sendo desenvolvida a partir de um processo de pesquisa com implementações ocasionais, de acordo com as oportunidades. A obra já foi apresentada e discutida em palestra e residência artística no MediaLab MX, na Cidade do México (2018), ${ }^{25}$ na Conferência Internacional Poderes do Som $(2019)^{26}$ e proposta para instalação num edital de ocupação artística - e, embora não aceita, a proposição foi um bom incentivo para planejar os aspectos técnicos da instalação. A própria pesquisa artística, no entanto, é a principal motivação do projeto.

24 Na verdade, a peça de Korsakov é inspirada provavelmente no voo do mangangá (o "bumblebee", do título em inglês), que é um tipo de abelha (e não besouro) do gênero Bombus, que inclui numerosas espécies, como a Bombus terrestris.

25 Sítio do espaço <http://medialabmx.org/>. A documentação fotográfica do evento pode ser conferida na página do Instagram do MedialabMx, no link: < https://www.instagram. com/p/BiYrRX-F8U9/ >, ambos acessados em 14/01/2021.

26 Evento realizado na Universidade Federal de Santa Catarina, em junho de 2019, Cf. < https://www.sonoridades.net/anais> (acesso em 14/01/2021) 
A proposta de abertura da escuta humana para o mundo estético (perceptos e afetos) e a subjetividade dos insetos relativiza as profundas diferenças entre esses dois modos de estar-no-mundo e ressalta a importância dos insetos na vida e na cultura humanas, propiciando um exercício de escuta atenta aos desafios do antropoceno. Escutar o antropoceno implica em adotar uma atitude ética/estética de abertura à percepção de outras formas de vida além das humanas. Se os riscos de um colapso ambiental se deixam perceber pelos efeitos devastadores da ação humana sobre o próprio habitat, buscar uma interação com seres de uma escala tão menor e frequentemente ignorada pode nos ajudar a desenvolver uma sensibilidade apurada (estética) para lidar com essas questões de vida e morte (éticas).

\section{Referęncias}

Brown, S; Merker, B; Wallin, N (orgs). 2001. The Origins of Music. MIT Press.

Castanheira, Carolina Parizzi. 2009. De institutione musica, de Boécio - Livro 1: Tradução e Comentários. Dissertação de Mestrado. Belo Horizonte: PPG Letras, UFMG

Chattopadhyay, Budhaditya. 2018. "Cosmic resonance: sounding outside, listening inside". Metaphonics (Stuart Hyatt org.). Heijningen: Jap Sam Books.

Chua, Daniel K.L. 1999. Absolute music and the construction of meaning. Cambridge: Cambridge University Press

Cory, Lara \& Fischer, Tobias. 2015. Animal Music: Sound and song in the natural world. Londres: Strange Attractor Press.

Crutzen, Paul \& Stoermer, Eugene. 2000. “The Anthropocene”. International GeosphereBiosphere Programme Newsletter, 41: 17-18.

De Waal, Frans. 2001. The Ape and the Sushi Master: cultural reflections of a primatologist. New York: Basic Books.

Drosopoulos, Sakis; Claridge, Michael (editores). 2006. Insect sounds and communication: physiology, behaviour, ecology and evolution. Taylor \& Francis,

Fuller, Matthew. 2010. “Art for animals" in Journal of Visual Art Practice, 9:1, pp. 17-33, Londres: Routledge

Fakotakis, N.; Ganchev, T. ; Potamitis, I. 2006. “Automatic Acoustic Identification of Insects Inspired by the Speaker Recognition Paradigm". ICSLP, Pittsburgh:USA, Sept 17-21, 2006, pp. 2126-2129.

Ingold, Tim. 2015 (2019 3ª reimpressão). Estar vivo: ensaios sobre movimento, conhecimento e descrição. Petrópolis: Vozes.

Krause, Bernie. 2013. A grande orquestra da natureza: Descobrindo as origens da música no mundo selvagem. Rio de Janeiro: Zahar.

Lefebvre, H. 1991. Elements de Rhythmanalyse, Paris: Syllepse

MacCagnan, D. H.B. 2008. Cigarra (Hemiptera: Cicadidae): emergência, comportamento acústico e desenvolvimento de armadilha sonora. Tese de Doutorado. Ribeirão Preto:USP

Marques, M.(editora). 2012. Cronobiologia. Revista da Biologia Volume 9 (3). São Paulo: USP.

Martinelli, Dario. 2007 “Zoosemiotics: Proposals for a Handbook". Imatra: International Semiotics Institute.

Pavan, G. 2008. Short course on bioacoustics. Taxonomy Summer School, 1-15 September. 
Rothenberg, David. 2013. Bug Music: How insects gave us rhythm and noise. New York, St. Martin's Press.

Schafer, R. Murray. 2011. A afinação do mundo. São Paulo: Unesp.

Shaw, David. 2018. "Anthropocene". Critical Posthumanism: <http://criticalposthumanism. net/anthropocene/\#_ftnref7->

Silva, Denise Ferreira da. 2007. Toward a global idea of race. Minneapolis: University of Minnesota Press

Slabekoorn, Hans. 2017. "Effects of noise pollution on animals". Anais do XXXV Encontro Anual de Etologia, Salvador-Bahia. < htps://xxxveaetologia.wixsite.com/2017> Acesso em $31 / 08 / 2019$

Smalley, Denis. 1986. Spectro-morphology and Structuring Processes. In: EMMERSON, S. (Ed.). The Language of Electroacoustic Music. London: Macmillan Press, pp.61- 93.

Smith, Suzanne. 2002. Characterizing the effects of airborne vibration on human body vibration response. Aviat Space Environ Med. 2002 Jan;73(1):36-45. PMID: 11817618. < https://pubmed.ncbi.nlm.nih.gov/11817618/ >

Takahashi, Yukio. 2011. A study on the contribution of body vibrations to the vibratory sensation induced by high-level, complex low-frequency noise. Noise $\&$ Health, vol.13, issue 50 , pp 2-8.

Taylor, H.- Introduction to Zoomusicology, < https://www.zoomusicology.com/ Zoomusicology/Introduction.html >

Viveiros de Castro, Eduardo. 2015. Metafisicas Canibais. São Paulo: Cosac Naify/ N-1 Edições.

Wood, Bernard. 2010. "Reconstructing human evolution: Achievements, challenges, and opportunities". Proceedings of the National Academy of Sciences. 107: 8902-8909

Yildiz, A. K.; Tarhan, S.; Özgüven, M.M. 2011. Acoustic Communication Among Insects And Its Use In Agriculture. Tokat: Gaziosmanpaşa University.

Zylinska, Joanna. 2014. Minimal Ethics for the Anthropocene. Ann Arbor: Open Humanities Press/ University of Michigan.

\section{The Anthropocene and the music of insects}

The self-perception of the human being as distinct from other beings is at the base of the threat to ecosystems posed by the Anthropocene. Anthropocene is therefore a dilemma of humanism. Could interspecies expression and communication (such as contact with the aesthetic world of insects) be able to activate critical listening and perspective reflection on the Anthropocene? The implications of a possible insect music are discussed here from multidisciplinary references (bioacoustics, ethology, cultural entomology, biomusicology), resulting from the reflections arising in the research process of the project 'entomúsica' (a neologism fusing the root word 'entomo' [insect], and music). Entomúsica, in this context, means: music made by, with or for the insects.

Keywords: anthropocene, zoomusicology, anthropomorphism, perspectivism

Recebido em: 2020-08-11

Aceite em: 2021-01-23 